\title{
Popular Culture, Art Making and the Case of G.I. Joe PatrickFahey
}

A trip back to Dubuque, lowa, a month after I had moved to lowa City led to a reunion with an eight-year-old boy named John Luke. John Luke is the son of a colleague I had worked with at a local high school and many accepted invitations to supper often led to discussions and private viewings of John Luke's artwork.

John Luke drew frequently and was especially successful in achieving the realism he thought was necessary to make his work "good." Frankly, when I first saw his drawings, I thought they had been copied. My reaction was not well accepted and John Luke and his father quickly let me know that this was not the case.

Apart from John Luke's level of sophistication, I was particularly intrigued with the subject of his drawings. His work reflected an intense preoccupation with the cartoon programs that filled his Saturday mornings and late afternoons during the week. Graphic portrayals of muscle-bound men, women with the perfect "Barbie doll" figures and villains wielding weapons of submission were all essential elements of his drawings.

This incident -- recovered several years later -- led me to look at the possible sources of ideas for children's artmaking and question in what way, if any, it affected what and how they created. I focused on the relationship between specific popular culture phenomena, which occupies most children's worlds, and its affect on an eleven-year-old child. Cartoons, games, toys and clothing which use the G.I. Joe motif are of exceptional -- but not extraordinary -- interest to a young boy named Ryan.

Ryan's intrigue with G.I. Joe began when he was introduced to several action figures his cousin brought to his house on Christmas Day when he was three years old. His immediate fascination was strong but, according to Ryan, "I had to wait until I was five to get one of my own."

Ayan "bought" into the mass culture critique marketing of G.I. Joes. He has over three dozen figures, six G.I. Joe video movies, G.I. Joe army fatigues, G.I. Joe toy vehicles and weapons, G.I. Joe comic book collections, and a G.I. Joe lunch box. In addition, Ryan spends a great deal of time collecting and cataloging G.I. Joe file cards, writing and drawing in a journal whose theme is G.I. Joe and creating vehicles and environments whose context is rooted in G.I. Joe adventures. 
An exhibit of artwork displayed in the school library illustrated a common schema used by Ryan. His work, featured in a "one-person show," was made out of styrofoam, bottle caps and hot glue. After going through the exhibit, I studied the list of titles Ryan gave to the vehicle sculptures he created. The exhibit included the following titles:

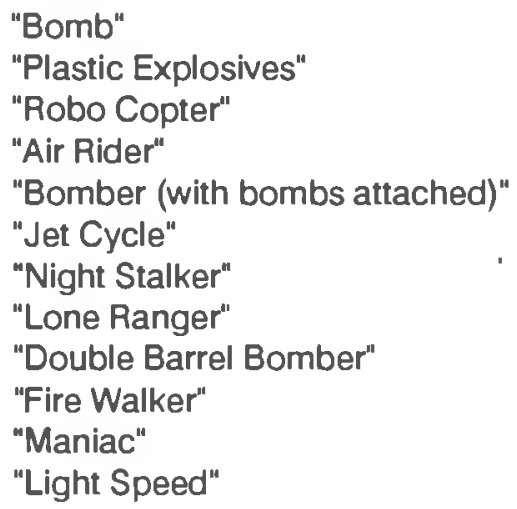

Ryan commented on his work in the exhibit in the following conversation:

Pat: Would you like to show me some of the things you made that were on display in the library?

Ryan: Sure... where is my favorite? "Night Stalker!" See...I shouldn't have glued this on here. (Points to bottle caps glued to the bottom of the vehicle that represent bombs.)

Pat: Why?

Ryan: Because this could have been a gun - that would have been more effective.

Pat: Earlier I went into the library and copied down the names of your vehicles. You had bombs and plastic explosives...?

Ryan: Well, I have...where's Bomber...Bombers Bomber? (He rummages through the box looking for this piece.)

Pat: $\quad$ Right there. (I pointed to its place in the box.)

Ryan: I named it "Bomber," because you know why?

Pat: Why?

Ryan: Because...one...two...three...four...five...bombs. 
Pat: Oh...so the bombs are attached. (Bottle caps were glued to the bottom of the vehicle with hot glue.)

Ryan: Andre got mad at me because I glued two caps together, but it's a bigger bomb that launches smaller bombs...posh...pow...phh...So it's really more than five bombs!

Pat: Are all of these in the G.I. Joe movies?

Ryan: No, I made them up! (Picked up another vehicle and pointed to several holes which cover the surface.) As you can see, I had weapons here. I brought my G.I. Joe weapons to put in.

Pat: You took them out?

Ryan: I didn't want anyone to steal them!

Another interest of Ryan's has been drawing in a journal -encouraged by his art teacher. Two-dimensional versions of his vehicle sculptures fill many of the pages. 
Figure 1. A Drawing By John Luke

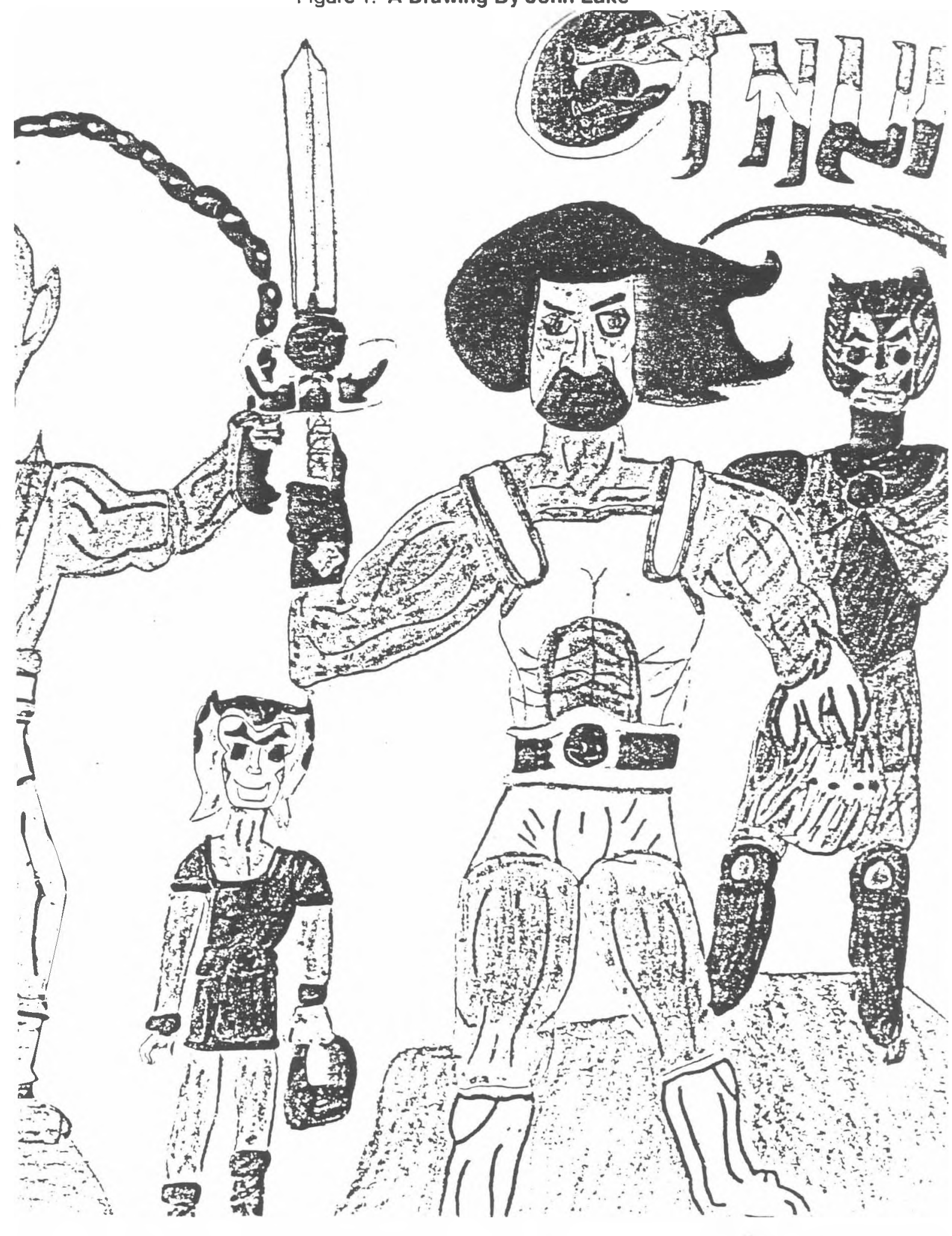

(49) 
Figure 2. Ryan's Drawings of His 3-D Vehicles
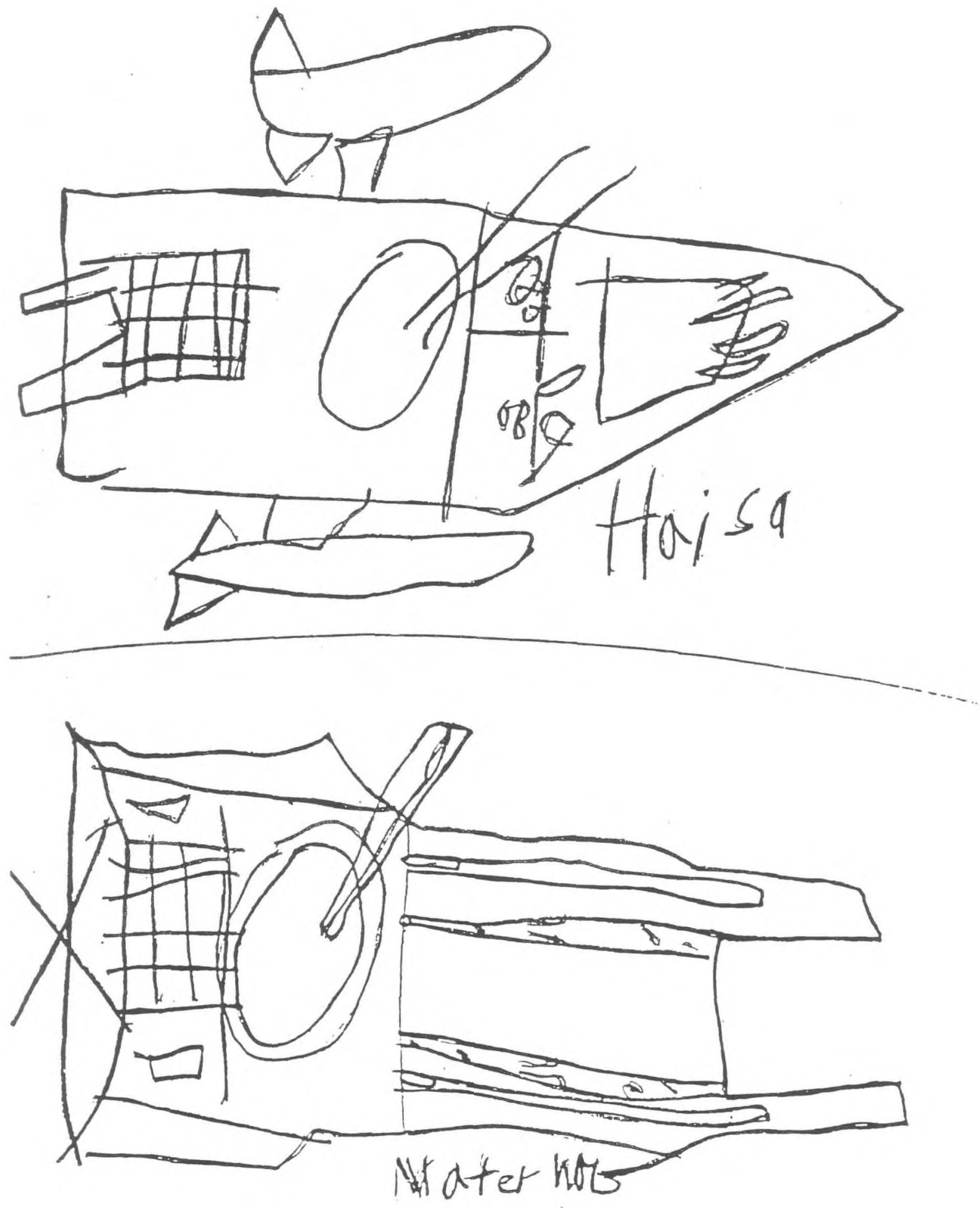

Working Papers in Art Education 1989 - 1990

(50) 
Figure 3. Ryan's Drawings of His 3-D Vehicles
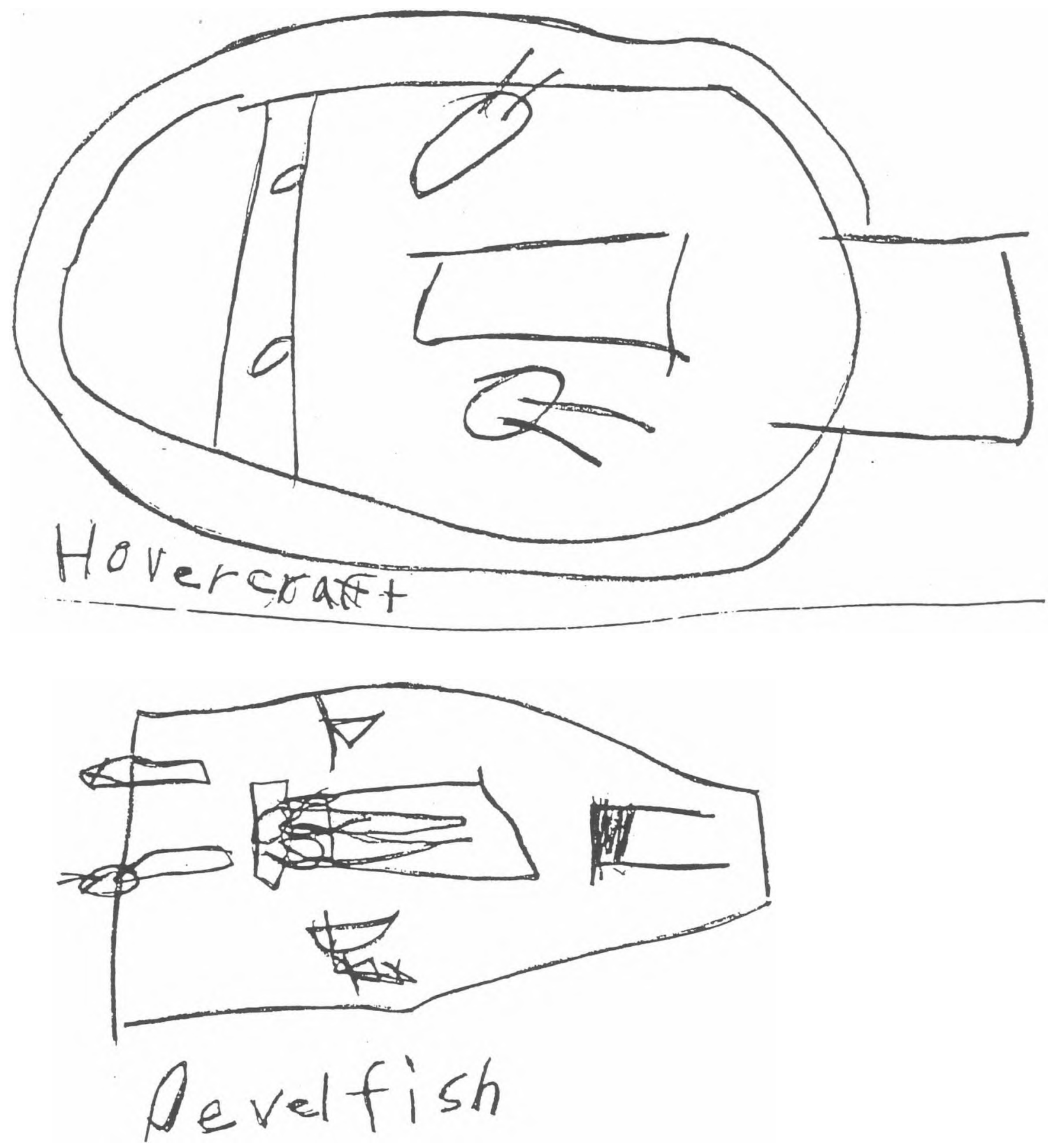

Working Papers in Art Education 1989 - 1990

(51) 
Elaborate scenes of conflict and plans for more sophisticated equipment, vehicles, and weapons are interspersed with Ryan's version of G.I. Joe file cards.

Figure 4. Ryan's Drawings for Protective Gear \& Weapons
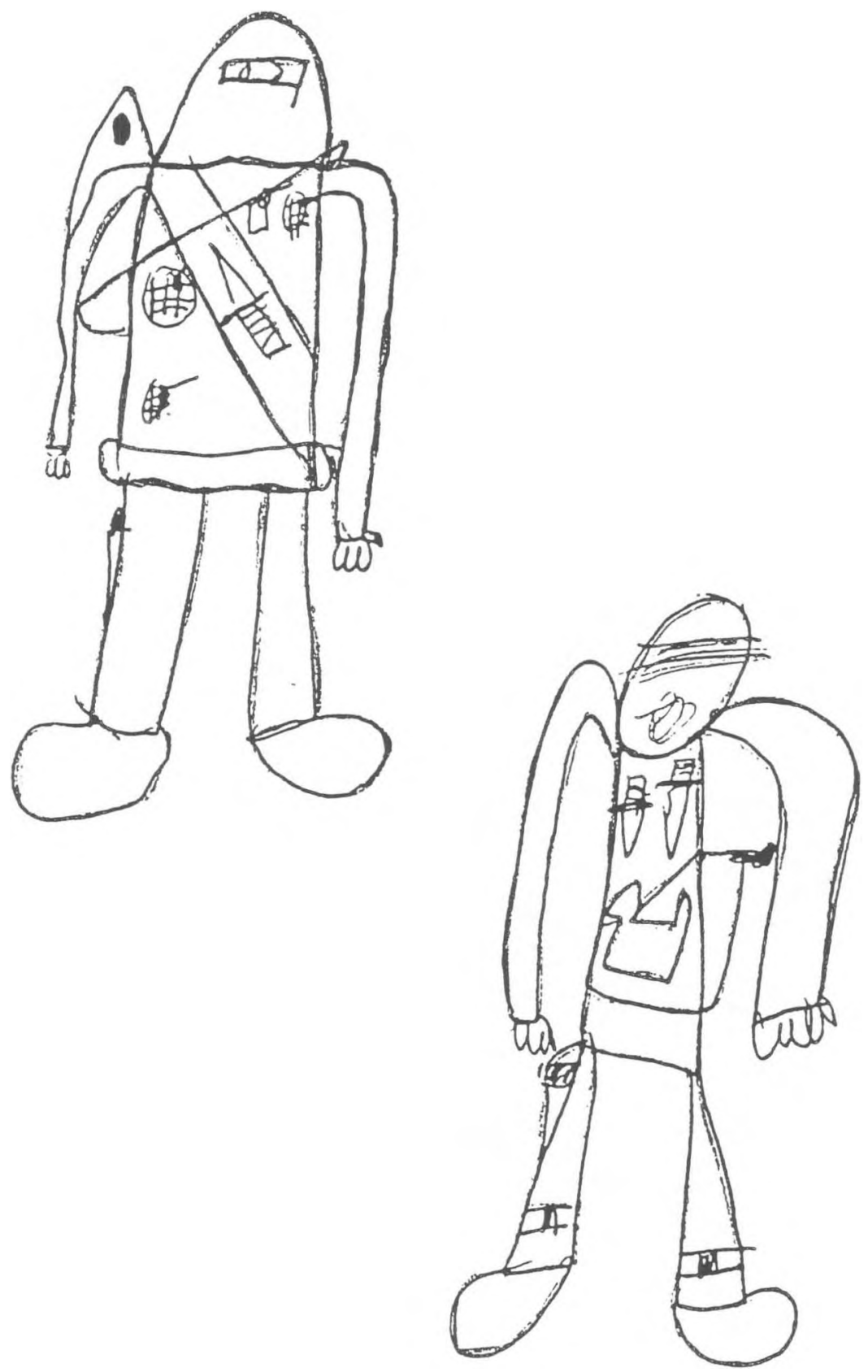

Working Papers in Art Education 1989 - 1990 
Figure 5. Ryan's Equipment \& Weapons Depicted in a Scene from His Journal

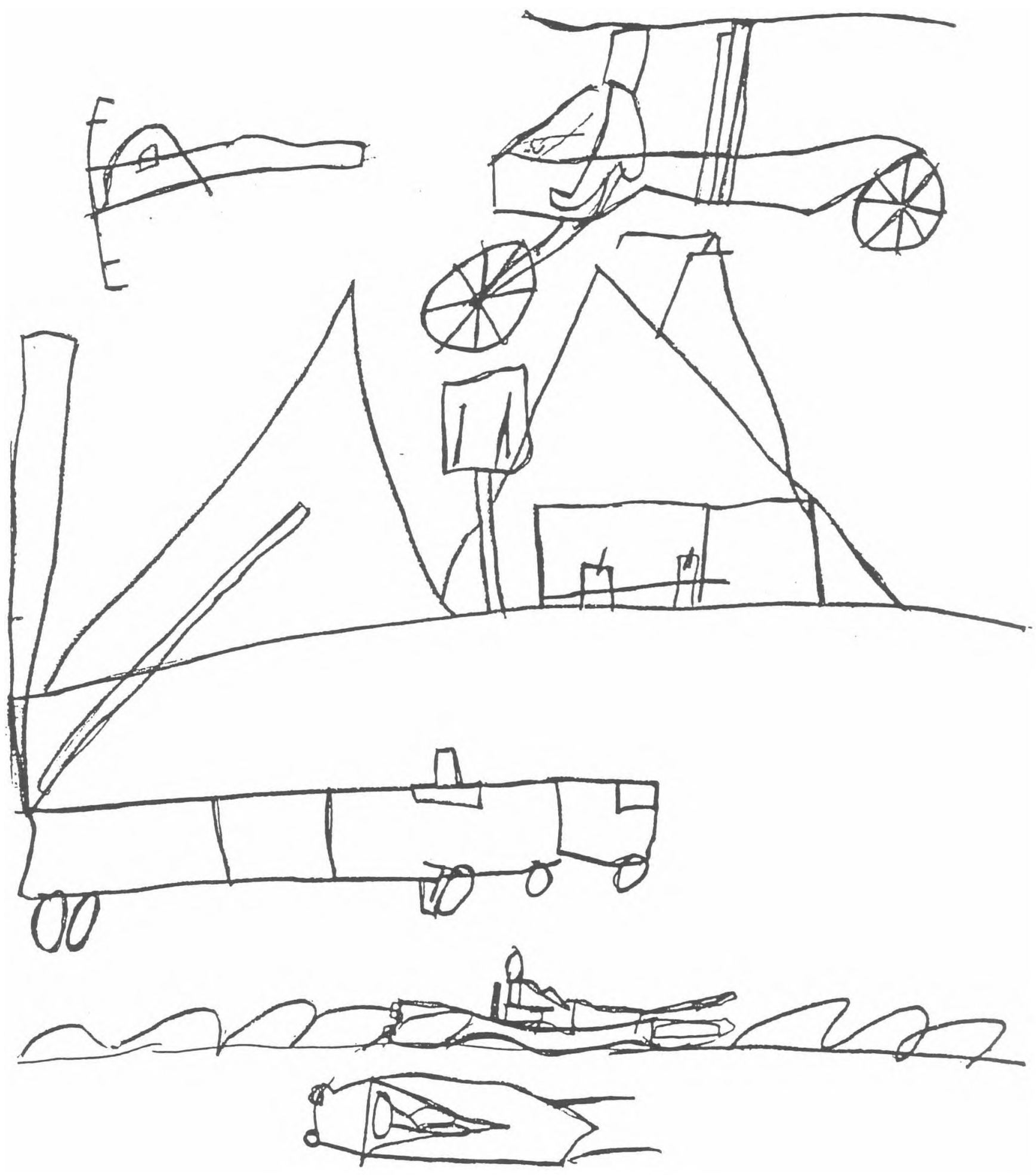

Working Papers in Art Education 1989 - 1990

(53) 
Ryan explained to me that with each purchase of a G.I. Joe figure, you receive a file card which gives the code name of the figure along with a brief biography and a list of characteristics and special abilities.

\section{Figure 6. G.I. Joe File Cards}
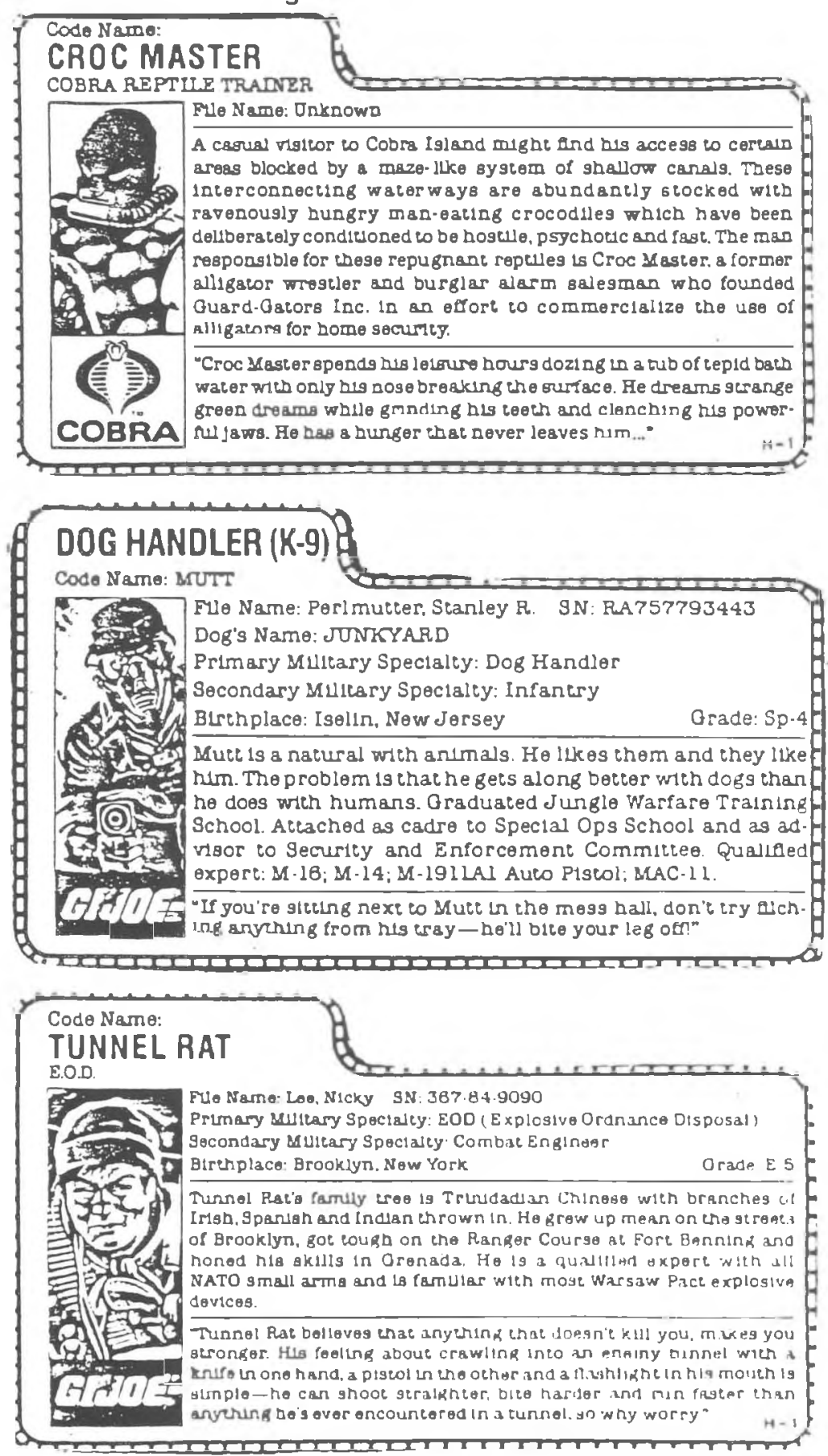

Working Papers in Art Education 1989 - 1990 
Ryan became fascinated with drawing the portraits of characters he imagined and creating biographies to accompany the drawing on file cards he designed -- many of these were kept in his journal.

Figure 7. G.I. Joe File Card: Ryan's Version

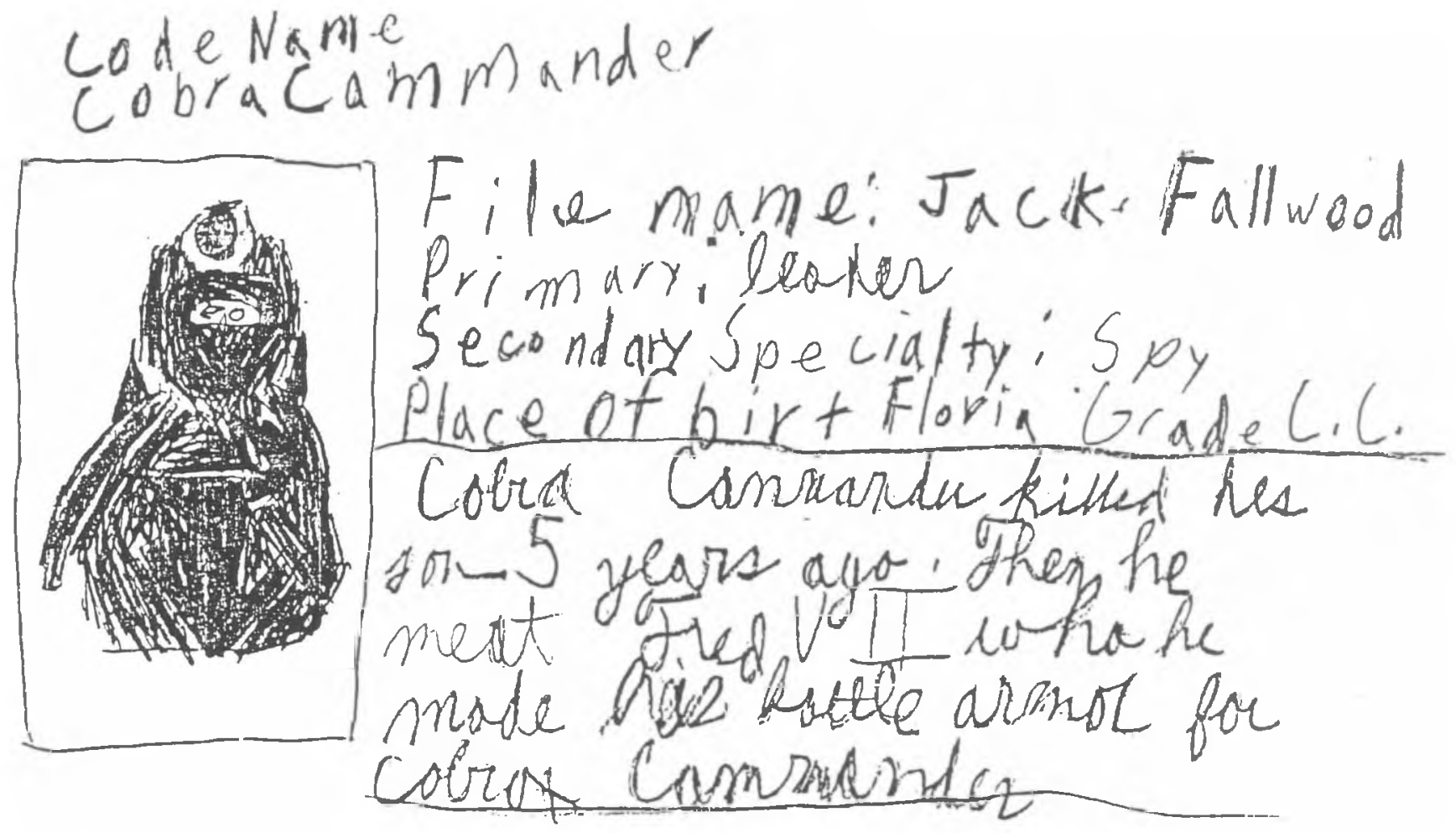

Throughout our conversations, the question of violence never came up despite the nature and setting in which Ryan viewed G.I. Joe. Yet, I knew this might be an issue for many parents and teachers. Certainly the violence and moral dilemmas presented to this eleven-year-old boy were evident in the toys, cartoons, videos, and comics he was confronted with almost daily. To find out its effect, I simply asked Ryan what he thought:

Pat: What do you think about violence and G.I. Joe?

Ryan: It depends. If a kid of three or four watches it, it's too violent. But, if a kid of eight watches it -- it's not.

Pat: How old are you?

Ryan: Eleven.

Pat: Would you say someone's who's in first grade shouldn't watch it? 
Ryan: Unh. They might...yeah, they could. Kindergarten shouldn't watch it though. I didn't watch it when I was in kindergarten.

It was evident that Ryan perceived the violence of G.I. Joe. Yet he viewed it in a realm separate from reality; he used it as an instrument to engage his play, fantasy, and creativity.

Roeske (1988) reported that "there has been an on-going debate over the affect that war toys such as G.I. Joe have on children that play with them" (p. 1). Many studies and organizations believe that these toys -- and even the play, conversation and artmaking they encourage -- have an adverse affect on children and prepare them for the notion of war.

In my discussions with Ryan's parents, teachers, and principal no one mentioned any exceptional aggressive tendencies in his personality. During my observations and our meetings, he exhibited what most would label "appropriate behavior" for a fifth grade student.

Sylvia Feinburg (1975) observed that art or creation dealing with war/violence is "a pervasive, insistent kind of activity, usually expressed when the child feels free of adult intervention or judgment" $(p .10)$. In Ryan's case, these objects, journals, and ideas evolved during unstructured free time or in the art class where he was left alone to develop his artwork. Observing her own child and his insistent desire to draw war pictures, Feinburg (1975) wrote, "and while war themes and war-related materials played a significant role in his play, little, if any, of this was transferred to Douglas' general behavior; even when involved in mock battles with friends, his play was of a cooperative nature" (p. 15).

Ryan had a strong identification with themes revolving around G.I. Joe. Yet, throughout numerous conversations, Ryan indicated that these characters were "make-believe." This relationship between identification and believability becomes important and is influential in understanding the source for Ryan's artmaking. It seems that Ryan's ability to reject the believability of G.I. Joe and his comrades, to understand its fantasy and, at the same time, his strong identification and assimilation of their qualities make him (perhaps most children) the perfect "receptacle" for this popular cultural phenomenon.

G.I. Joe has offered Ryan a way to project and participate in the artmaking process using images, characters, and themes which are important and personal to him at this time in his life. Although much of his work evolves from a common source, his creations are continually changing. They are not stagnant nor are they mere reproductions of images and ideas created by someone else. And although some may perceive his images as a cliche, stereotype, or typification, the personal meaning and identification Ryan attaches to his work may preclude this conclusion. Zurmuehlen, Sacca and Richter (1984) provided insight into the question of stereotypes: 
In

often mentioned that an object is drawn without any background, suggesting that to their students, context is either unnecessary or unimportant for such conventional images. Perhaps this is because, as we heard over and over, a stereotype is easily recognized, so it does not require a situation for identification. It is intriguing to reflect on such contextless images as physical analogies for the attitude characterized by many of the teachers as lack of emotional involvement. This attitude was attributed variously to experiences mediated through commercial promotions, comic strips, TV, colored slides of art, magazine representations of art, and other people's notions about art. In one form or another these art teachers acknowledged the importance of social sanctioning and social situations in developing images and concepts in art. However, they feared that "students lose their own identities as persons." Stereotypes in art, then, become a manifestation of that meaninglessness. Mute evidence for the value which these art teachers attach to direct experience may be noted in the frequency and vividness with which they spontaneously described their own early recollections as they struggled to interpret stereotypes, schemata, and personal meanings.

(p. 70)

Ryan's artwork leaves this realm because of the meaning he has attached to his creations. His work illustrated inventiveness and creativity in dealing with the popular cultural phenomenon of G.I.

stories that emerged from Ryan's work perhaps became a kind of metaphor -a way to bridge this "media," G.I.

artwork is nestled in an interacting matrix of life stories and popular culture. And he continued to explore his interest in new and evolving ways. A video play about a boy named Buddy who goes to the Museum of Future Vehicles, additional journals and the introduction of new characters and equipment demonstrated that he had taken popular cultural influences -- often the source for stereotypes -- to another level in which they were used to interpret and create art that is meaningful to him.

Boyer (1987) acknowledged the importance of this type of phenomenological investigation and discussed how it might serve as the foundation for the development of an art curriculum that allows students to evolve and expand on their interests and traditions. Her approach to understanding cultural assumptions and their influence on preferences and attitudes shaped during the artmaking process seems particularly appropriate in this situation. Boyer (1987) stressed that "students can continue to clarify their own beliefs and cultural assumptions as they create new scenarios in an art form of interest to them." (p. 102)

Working Papers in Art Education 1989 - 1990 
Ryan's creations then, become an examplar for this important search. Not directed by any absolute standard of aesthetics -- Ryan was allowed the opportunity to explore, examine, ask questions and create art through and in a context that had meaning to him.

\section{References}

Boyer, B. (1987). Cultural literacy in art: Developing conscious aesthetic choices in art education. In Blandy, D. \& Congdon, K. (Ed.). Art in a democracy. New York: Teachers College Press.

Feinburg, S. (1975, January). Children play at war. Learning, pp. 10-16.

Roeske, T. (1988). G.I. Joe field notes \#5. Unpublished paper.

Zurmuehlen, M., Sacca, E., \& Richter, I. Brazilian, Canadian and U.S. art teachers interpret as stereotypes in their students' art. In cross cultural research in art education, pp. 45-71. 